\title{
Apical Left Ventricular Hypertrophic Cardiomyopathy: A Case Report
}

\author{
Ramachandran Muthiah \\ Thoothukudi Medical College Hospital, Thoothukudi, India \\ Email: cardioramachandran@yahoo.co.uk
}

How to cite this paper: Muthiah, R. (2016) Apical Left Ventricular Hypertrophic Cardiomyopathy: A Case Report. Case Reports in Clinical Medicine, 5, 308-329. http://dx.doi.org/10.4236/crcm.2016.59049

Received: August 15, 2016

Accepted: September 25, 2016

Published: September 28, 2016

Copyright $\odot 2016$ by author and Scientific Research Publishing Inc. This work is licensed under the Creative Commons Attribution International License (CC BY 4.0).

http://creativecommons.org/licenses/by/4.0/

\begin{abstract}
Apical hypertrophic cardiomyopathy (apical HCM) is a rare variant of hypertrophic cardiomyopathy with a prevalence of $1 \%-2 \%$ in Asian population and carries a benign prognosis. It is usually silent in early stages and manifests in adults with a suspicion of typical ECG changes of giant $\mathrm{T}$ wave inversion in left precordial leads. Transthoracic echocardiography is the mainstay of non-invasive diagnosis and provides a heterogeneous appearance of its morphological features with a spade-shaped LV (left ventricular) cavity. Background of this case study describes the apical HCM in an asymptomatic male at the age of 54 years old and also predicts the mixed and mid-ventricular forms of left ventricular HCM at this region of Thoothukudi in India.
\end{abstract}

\section{Keywords}

Apical Hypertrophy, Left Ventricle, Spade-Shaped LV Cavity, Echocardiography, Yamaguchi Syndrome, Apical Ballooning Syndrome

\section{Introduction}

Apical hypertrophic cardiomyopathy (apical HCM) is an atypical phenotype of nonobstructive HCM (hypertrophic cardiomyopathy) and it is more prevalent in Japanese people [1]. Usually it is considered as a benign condition and is detected incidentally by echocardiography.

\section{Review of Literature}

Apical HCM was first described in Japan. Sakamoto et al. first described the ECG pattern of apical HCM in 1976 [2] in Japanese patients. But it was Yamaguchi that described the syndrome and its ventriculographic features in 1979 [3]. Kubo and col- 
leagues [4] used echocardiography in a cohort of 264 patients to define the imaging characteristics and Chen et al. [5] utilized 2D echocardiography to further classify apical HCM and to assess the wall thickness. Kitaoka et al. found the apical HCM in 15\% of Japanese and 3\% of American patients of HCM. Apical HCM constitutes 8\% - 10\% [6] [7] of non-Japanese population. It is rare in the West (1 to 11\%) [8], but more common in oriental people and accounts for $13 \%-41 \%$ of all variants of HCM among Asian individuals [9], $16 \%$ - 41\% of entire HCM population in Chinese [10] and $24.5 \%$ of all HCM in Taiwan [11]. Sakamoto et al. noticed the benign prognosis of apical HCM in a study on 200 patients in Japan [12].

Published Indian studies are limited for comparison, so this case had been reported.

\section{Case Report}

A 54-year-old asymptomatic male was referred for echocardiographic evaluation due to an LVH (left ventricular hypertrophy) pattern of ECG changes as shown in Figure 1 and a normal X-Ray chest as in Figure 2. His pulse rate was $88 \mathrm{bpm}$ and blood pressure 130/80 mmHg. Blood chemistry revealed normal. He had no physical findings. Transthoracic echocardiographic images revealed an asymmetric apical hypertrophy (AAH) in four chamber views and a concentric apical hypertrophic pattern in apical long axis views as shown in Figures 3-10 given below. Screening of family members revealed normal and the patient was given small dose of ACE (angiotensin-converting enzyme) inhibitors such as ramipril $1.25 \mathrm{mg}$ daily and advised close follow up.

\section{Discussion}

\subsection{Etiopathogenesis}

Hypertrophic cardiomyopathy (HCM) is the most common genetically transmitted cardiovascular disease and it is usually familial with heterogeneous expression. Several disease-causing mutations in genes encoding proteins of the sarcomere have been reported [13]. A family history is more common in patients with asymmetric septal hypertrophy (ASH) than with apical hypertrophic cardiomyopathy (AHCM). Apical hypertrophic cardiomyopathy is frequently sporadic, a few families have been reported with autosomal dominant inheritance and a sarcomere gene mutation in the alphacardiac actin gene (Glu101Lys) has been shown to consistently producing the apical HCM phenotype [14]. Alpha and beta cardiac myosin heavy chain (MHC) mutations affect the polypeptides crucial to the structure of myofibrils and might be responsible for the myocyte and myofibrillar disarray, characteristic of familial HCM. The cause of sporadic apical HCM is unknown, but genetic, racial and even environmental factors could be responsible and many have lesser degree of hypertrophy, the outflow gradients are usually lacking, symptoms are often absent and the disease is detected only by echocardiography. An association with HLA-DR ${ }_{2}$ antigen in patients with apical HCM was recently reported in Japan [15]. Other investigators consider a secondary genesis as the underlying pathogenetic mechanism, i.e., hypertension or heavy physical exercise [16]. 


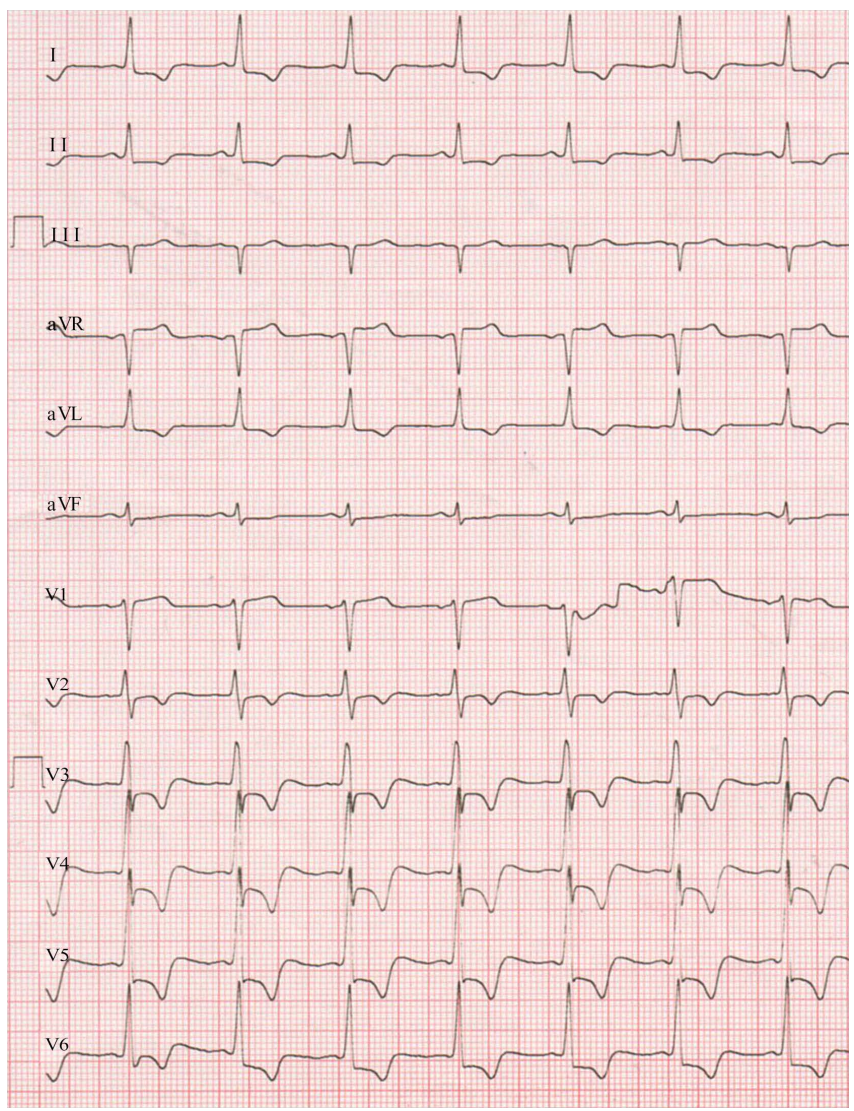

Figure 1. ECG showing the "strain" pattern-deep T wave inversion $(7 \mathrm{~mm}$ ) with $5 \mathrm{~mm} \mathrm{~J}$ point depression in precordial and limb leads and a positive Sokolow-Lyon index $\left(\mathrm{SV}_{1}+\mathrm{RV}_{5}=50 \mathrm{~mm}\right)$ as a sign of LVH (left ventricular hypertrophy) $(1 \mathrm{mV}=5 \mathrm{~mm}$ standardization).

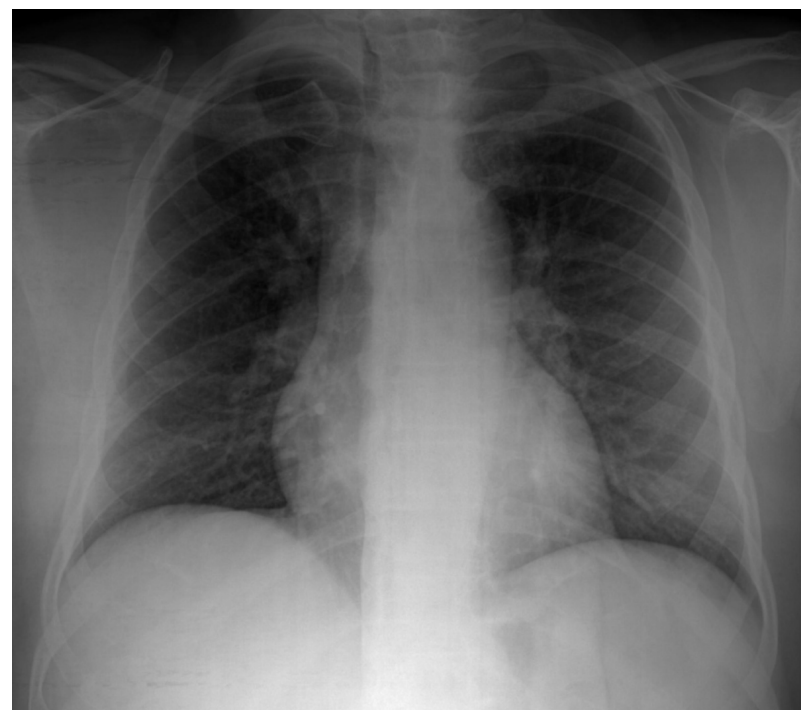

Figure 2. X-ray chest PA (posterior-anterior) view revealed normal. 


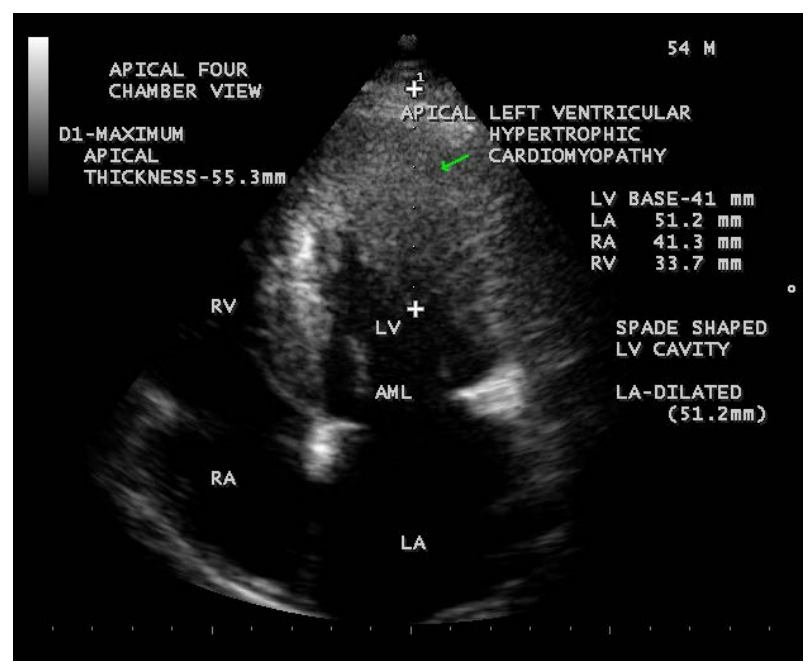

Figure 3. Showing apical HCM in end diastole-mitral valve fully opened position. Arrow mark indicates apical hypertrophy.

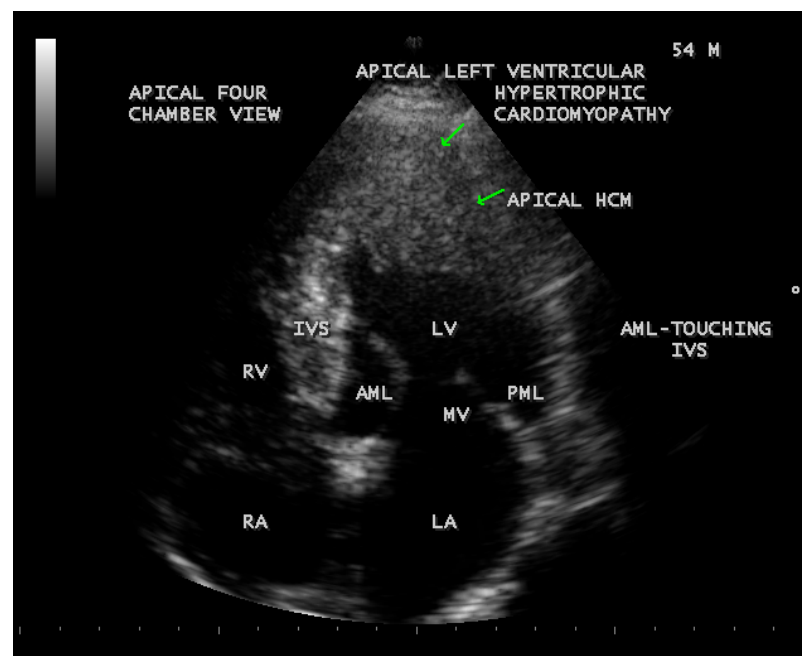

Figure 4. Showing apical HCM-AML (anterior mitral leaflet) elongated and touching the IVS (interventricular septum). Arrow marks indicate apical hypertrophy).

Left ventricular hypertrophy is a gross anatomic marker and major determinant of the clinical feature of the disease [17]. The increased left ventricular mass is almost entirely due to increased wall thickness and the left ventricular cavity is usually small or normal in size. The distribution of wall thickening varies so greatly in HCM and there is no single classic morphologic pattern. Relatives with same genetic substrate usually have dissimilar pattern of left ventricular hypertrophy. All possible patterns of hypertrophy have been observed and occasionally, HCM shows segmental wall thickening confined to the left ventricular apex, a morphological form that in Japan has been associated with a spade shaped deformity of the left ventricle and giant negative $\mathrm{T}$ waves in electrocardiography (ECG) [18]. In some patients with HCM have substantial hyper- 


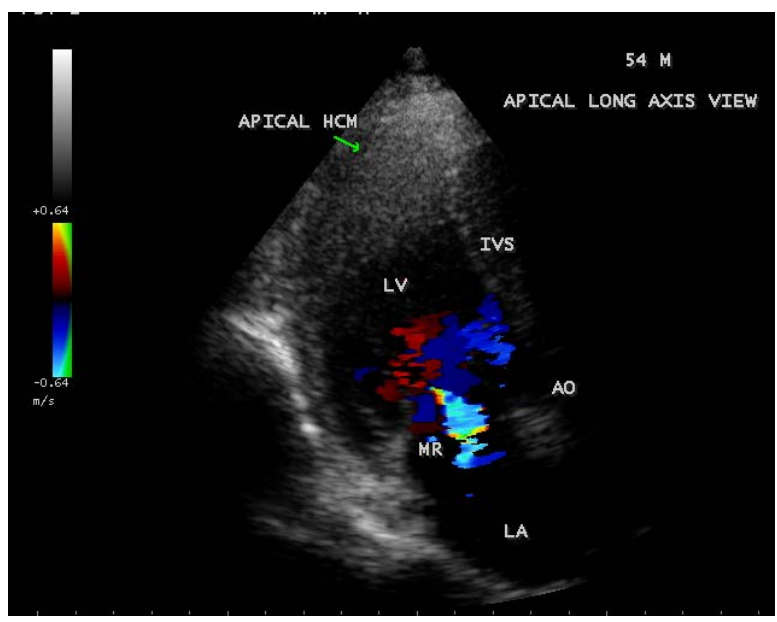

Figure 5. Showing mild mitral regurgitation, due to trauma on AML (anterior mitral leaflet) as the result of contact with septum and hypertrophied segment during cardiac cycle in apical long axis view. Arrow mark indicates apical hypertrophy).

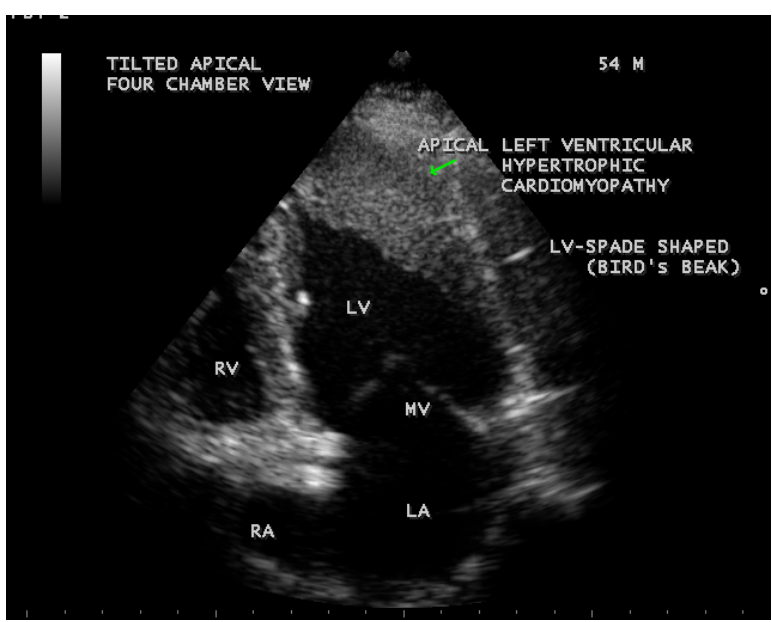

Figure 6. Showing the "spade-shaped" or "bird's beak" LV (left ventricular) cavity at the onset of systole-mitral valve begins to close) in Tilted apical view. Arrow mark indicates apical hypertrophy.

trophy in unusual locations such as the posterior portion of the septum, the posterobasal free wall and the mid-ventricular level [19].

Embryologically, asymmetric septal hypertrophy results from postnatal persistence of a normal anatomic feature of the developing heart [20] [21]. The disproportionate thickening of the ventricular septum is characteristic of the normal embryonic and fetal human heart. Even though prominent hypertrophy may be found in infants, the typical patient develops left ventricular hypertrophy during adolescence [22] after a period of prolonged latency. However, HCM may occur at any time in adult life due to mutation of cardiac myosin-binding protein C [23]. 


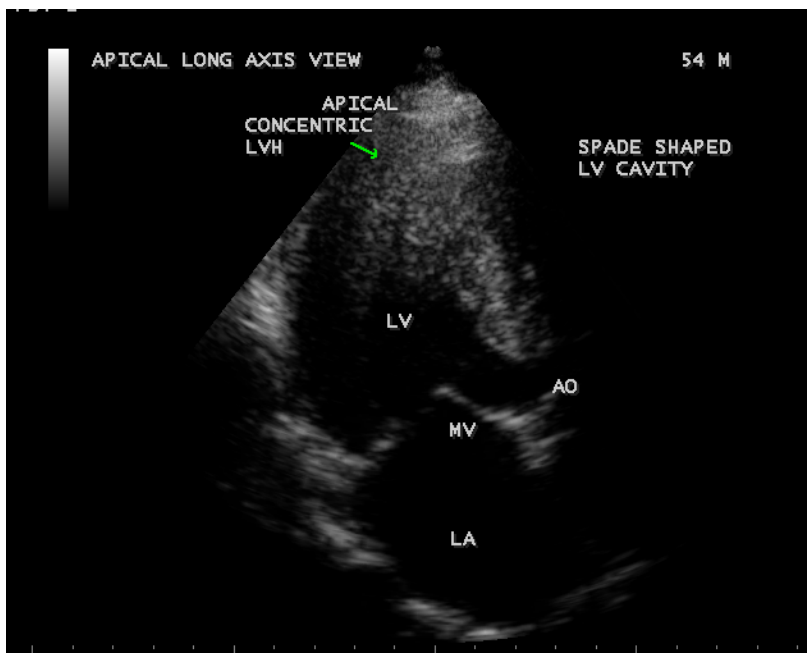

Figure 7. Showing the concentric pattern of apical hypertrophy and a spade-shaped LV (left ventricular) cavity in apical long axis view. Arrow mark indicates concentric hypertrophy of LV apex).

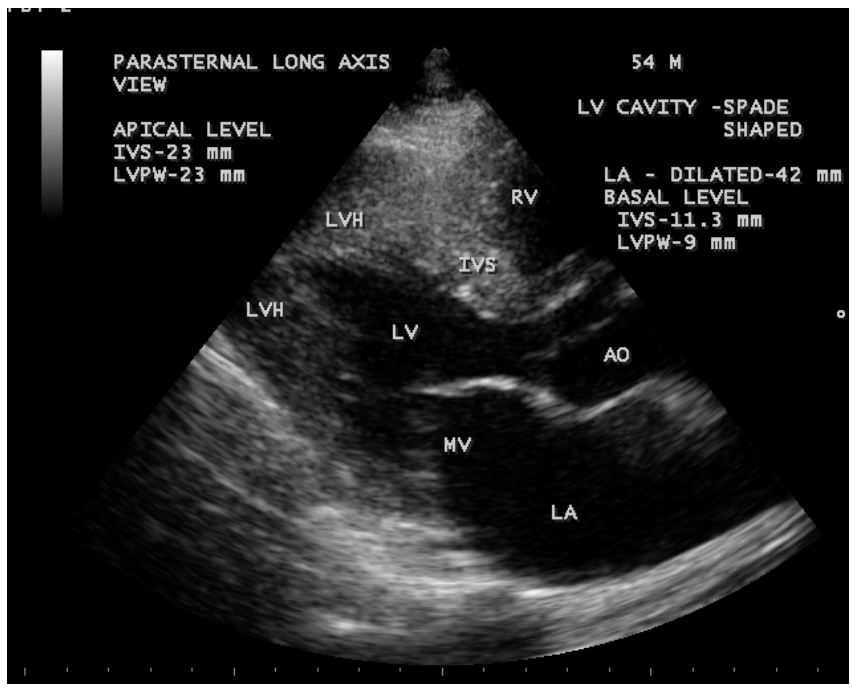

Figure 8. Showing the hypertrophied apical segment and a spade shaped LV (left ventricular) cavity in Parasternal long axis viewApical to basal ratio $(\mathrm{ABR})=2: 1$ (apical IVS $=23 \mathrm{~mm}$, Basal IVS $=11.3 \mathrm{~mm}$ )-suggesting apical HCM (hypertrophic cardiomyopathy), i.e., $\mathrm{ABR}>1)$.

\subsection{Morphological Types of Apical HCM}

According to the distribution of hypertrophied musculature, the morphologic sub classification as "true apical" phenotype (hypertrophy of only the apical segment below the papillary muscle) and "distal-dominant" phenotype (hypertrophy extended into the middle LV segments) have been recently recognized in North America [24]. Mid ventricular obstruction or apical obliteration was frequently found in patients with distaldominant form and it is more often symptomatic and more likely to develop cardi- 


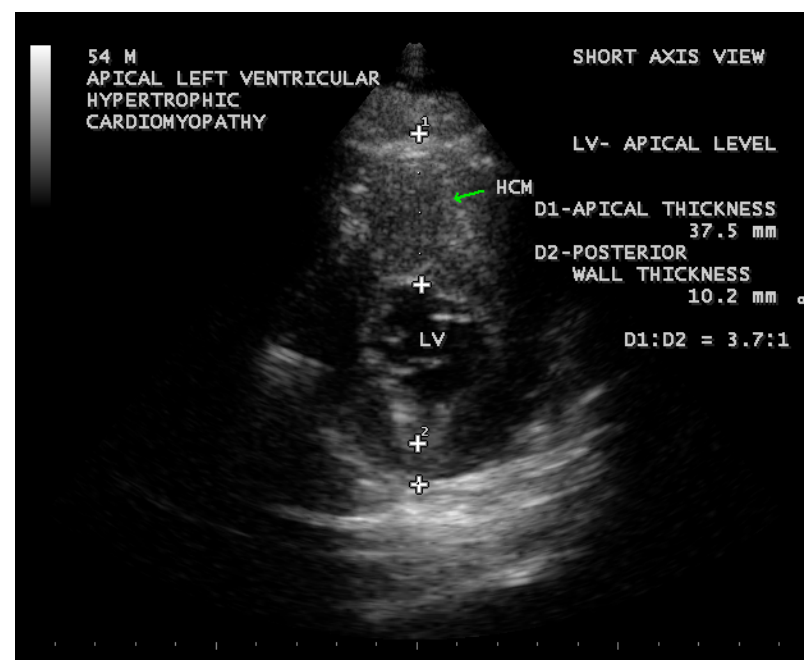

Figure 9. Showing the Apical HCM in short axis view. The ratio of apical thickness to posterior wall thickness is 3.7:1, suggesting apical HCM (hypertrophic cardiomyopathy, i.e., the ratio is $>1.5: 1$ ).

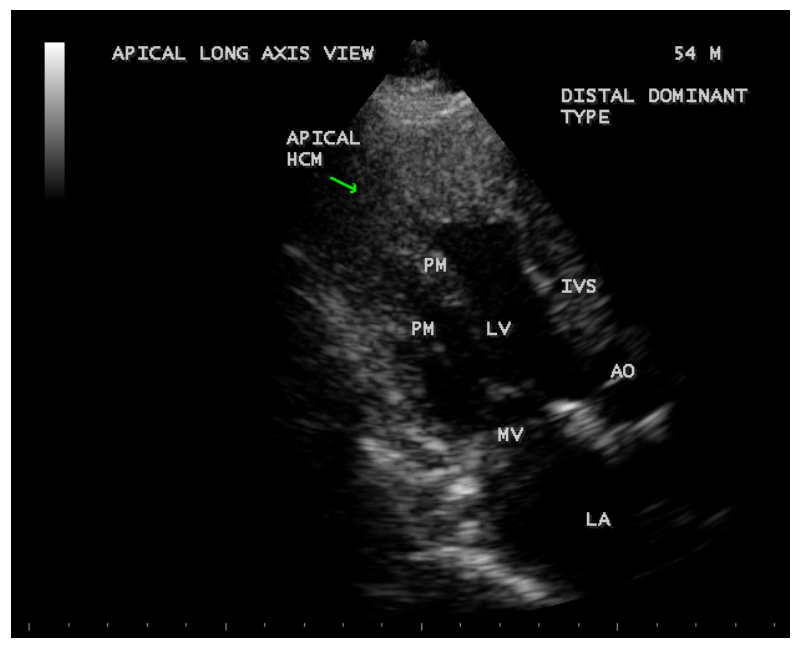

Figure 10. Apical left ventricular long axis view showing the hypertrophy confined to LV (left ventricular) apex below the papillary muscles (PM) and the papillary muscles are not hypertrophied.

ovascular events. Other investigators have separated the AHCM into "pure form" (apical segment only) and "mixed form" (hypertrophy extending into other segments) [25]. Based on CMR (cardiac magnetic resonance) imaging, apical HCM is divided into 3 types as true apical form, a type with additional asymmetric involvement of ventricular wall segments and a type with symmetric involvement of ventricular wall segments. Generally, apical HCM is divided into two groups as isolated asymmetric apical HCM (pure AHCM) and co-existent hypertrophy of interventricular septum (mixed AHCM) [26]. The pure form is predominant in Japanese, while the mixed form has been linked to Caucasian patients [27] [28]. 
A relatively normal-sized, diffusely hypokinetic left ventricle with an unexplained, pathological hypertrophy is termed as "burned-out" hypertrophic cardiomyopathy.

\subsection{Clinical Presentation}

Clinical expression of apical HCM is highly variable. Apical HCM may manifest early in adulthood [29] and most series reported a mean age of atleast 41 years [30]. About $54 \%$ of patients with apical HCM are symptomatic and the most common symptoms are chest pain, followed by palpitations, dyspnea and syncope. According to one large published series, AHCM presented with atypical chest pain (14\%), palpitations (10\%), dyspnea (6\%), presyncope/syncope (6\%) [31]. Atypical chest pain is the most frequent symptom and typical angina may also occur due to diminished vasodilaltory reserve. Atrial fibrillation (12\%), apical myocardial infarction (10\%), ventricular arrhythmia and apical thrombosis with subsequent embolization may occur up to $33 \%$ of cases [32]. [33]. The mismatch between fixed epicardial blood supply and large muscle mass leads to sustained myocardial ischemia and necrosis resulting apical aneurysm which may complicate with ventricular tachycardia. A 65-year-old Indian woman having apical aneurysm and presented with long standing angina had been reported [34].

Apical hypokinesis and aneurysm formation may also result from midventricular (mid-cavity) obstructive type of hypertrophic cardiomyopathy and transient LV (left ventricular) apical ballooning, a characteristic feature of Takotsubo cardiomyopathy (stress cardiomyopathy or apical ballooning syndrome or broken-heart syndrome) which was originally described in Japan in 1990 and it is most commonly seen in elderly post-menopausal women, characterized by ST segment elevation in anterior precordial leads with elevated cardiac enzymes and may be due to excess catecholamines (diffuse microvascular spasm or dysfunction, resulting myocardial stunning or direct myocardial toxicity), coronary vasospasm and triggered by emotional or physical stress. It may presents with sudden onset of chest discomfort, shortness of breath and reversible within weeks to months. A criteria formulated by Mayo clinic as regional hypokineses with ECG evidence of ST-segment elevation in the absence of obstructive coronary artery disease, pheochromocytoma or myocarditis to diagnose this condition. During the event, the shape of LV cavity resembles the fishing pot of Japanese (Tako-tsubo) to trap octopuses and so it is called as Takotsubo cardiomyopathy. The typical form of this cardiomyopathy is apical type, characterized by systolic apical ballooning with hypokineses of apical and mid segments and hyperkineses of basal walls. The atypical variants such as mid-ventricular type (hypokineses restricted to mid-ventricle with sparing of apex), basal type (hypokineses of base with sparing of mid-ventricle and apex), focal type (dysfunction of a segment, usually anterolateral) and global type (global hypokineses) were also described.

\subsection{ECG Features}

The most common ECG findings are negative $\mathrm{T}$ waves in the precordial leads, found in $93 \%$ of patients (a depth $>10 \mathrm{~mm}$ in $47 \%$ ) and a documented left ventricular hypertro- 
phy on imaging is seen in 65\% of patients with HCM. Giant T wave negativity (defined as depth or voltage $>1 \mathrm{mV}$ or $1.2 \mathrm{mV}$ in any of the leads) in the left precordial leads is the hallmark feature of apical HCM as a result of balance of electrical forces emanating from the left versus the right ventricle [35] due to abnormal repolarization of hypertrophied apical musculature. Yamaguchi et al. published a report in 1979 determining that apical hypertrophy is the only specific hypertrophic pattern that shows characteristic ECG abnormalities, i.e., giant negative $\mathrm{T}$ waves and high QRS voltage in the left precordial leads. Giant negative T waves are characteristic of hypertrophic cardiomyopathy with predominant apical thickening, especially in patients from the Pacific Rim, called as Yamaguchi syndrome [36].

Altered repolarization changes of ventricular myocardium may produce ST segment/ $\mathrm{T}$ wave changes in $70 \%$ of cases of left ventricular hypertrophy. There is significant variability on manifestation of strain pattern as minimally inverted or $>5 \mathrm{~mm}$ depth, asymmetric $\mathrm{T}$ waves with rapid return to baseline and terminal positivity, depression of the $J$ point, $T$ wave inversion in lead $V_{6}>3 \mathrm{~mm}$ and greater in $V_{6}$ than $V_{4}$ [37] and high QRS voltage ( $R$ in $V_{5}>26 \mathrm{~mm}, S$ in $V_{1}+R$ in $V_{5} \geq 35 \mathrm{~mm}$ - positive Sokolow-Lyon index as a sign of LVH).

In apical HCM, larger degree of T wave inversions are seen and it's depth does not correlate with severity of apical hypertrophy [38]. Presence of giant T wave inversions in Japanese HCM patients has been identified as a predictor of favourable outcome and it is more common in sporadic cases of apical HCM. Reports from outside Asia would suggest, however, that apical hypertrophy is uncommonly accompanied by marked $\mathrm{T}$ wave inversion and associated with adverse outcome in some patients. This heterogeneous morphologic expression even in first degree relatives is due to great dissimilarity in the pattern of left ventricular wall thickening [39]. In some non-Japanese studies, T wave negativity was often less pronounced and not necessarily localized to the precordial leads [40].

Abnormal ECG changes and no echocardiographic evidence of hypertrophic cadiomyopathy is seen in some patients due to abnormal gene in first degree relatives and called as carrier or preclinical state of hypertrophic cardiomyopathy. Incidence of deep $T$ inversion may diminish considerably with advancing age. Myocardial infarction with a secondary apical LV aneurysm may occur in $10 \%$ of cases, that might determine the disappearance of the giant T waves in apical HCM and the "spade" shaped LV configuration may become "bottle-gourd "shaped. In normal variant of hypertrophic cardiomyopathy (HCM), the LV (left ventricular) cavity is usually "banana" shaped. However, in some cases, non-giant $\mathrm{T}$ waves may become a giant one on later life. The $\mathrm{T}$ wave changes associated with ischemia are usually narrow and symmetric (deep T wave inversion) and "CVA (cerebrovascular accident)- $\mathrm{T}$ wave pattern" is associated with marked QT prolongation especially in subarachnoid hemorrhage.

\subsection{Transthoracic Echocardiography}

The preferred initial imaging test is Transthoracic Echocardiography and it is the most frequently utilized diagnostic modality [41]. Hypertrophy (apical or elsewhere) is de- 
fined as a compacted myocardial wall thickness in diastole greater than or equal to 14 $\mathrm{mm}$ and it is $15 \mathrm{~mm}$ as a threshold in conventional echocardiographic measurements, which was performed perpendicular to the axis of the wall and at the point of maximal thickness in short axis view at apical level as shown in Figure 9. In apical hypertrophic cardiomyopathy, the asymmetric hypertrophy of the left ventricle is predominantly confined to LV apex as shown in Figures 3-10, with a maximal apical thickness $\geq 15$ $\mathrm{mm}$ and a ratio of maximal apical to posterior wall thickness $\geq 1.5$ based on two dimensional echocardiography is a diagnostic criterion of apical HCM [42]. Figure 9 shows the maximal apical thickness of $37.5 \mathrm{~mm}$ and a ratio of maximal apical to posterior wall thickness $(10.2 \mathrm{~mm}) 3.7: 1$ (>1.5:1) in short axis view, satisfying the diagnosis of apical HCM in this patient.

Relative hypertrophy was defined as the absence of hypertrophy (wall thickness $<14$ $\mathrm{mm}$ ) but with the apical wall thickness greater than the basal thickness (apex:base ratio (ABR) wall thickness $>1$ ). An apical- to-basal LV wall thickness ratio of $1.3-1.5$ is diagnostic of apical HCM [43] and in this patient, it is 2:1 in parasternal long axis view as shown in Figure 8.

Apical HCM is characterized as concentric, circumferential hypertrophy of the entire apex due to apical left ventricular thickening of the anterior and posterior walls, resulting in a spade-like morphology of the left ventricular cavity during end diastole in LV long axis view of MRI and RAO projection of angiography. A subtype of apical HCM in which the distribution of hypertrophied myocardium proved to be confined to the apical lateral wall (AAH-asymmetric apical hypertrophy) and cannot be evaluated in long axis MRI or RAO projection in angiography and this subtype was called as nonspade apical HCM in short axis images of MRI [44]. A recent long-term study showed that patients with non-spade apical HCM may develop the typical spade-like configuration after some years [45]. Thus, the non-spade type is possibly an early stage of apical $\mathrm{HCM}$ and giant negative $\mathrm{T}$ waves are common in both types.

A criteria was formulated to diagnose apical HCM in a distinct phenotype [46] not captured by existing disease classification. This phenotype comprises

1) -Two essential criteria

-Deep ECG T wave inversion

-Relative apical hypertrophy $(\mathrm{ABR}>1)$

2) -Four minor or supportive criteria

-Myocardial scarring by LGE CMR (late gadolinium enhancement cardiac magnetic resonance)

-Presence of apical aneurysm or microaneurysm

-Left atrial dilatation

-Apical cavity obliteration $>20 \mathrm{~mm}$

The presence of two or more of four minor criteria is the supportive evidence of apical HCM. The differential features of Japanese and non-Japanese type of apical HCM is shown in the Table 1 given below.

In transthoracic echocardiography, the lateral wall hypertrophy is more than the 
Table 1. Showing the differential features of Japanese and Non-Japanese type of HCM (hypertrophic cardiomyoapthy).

\begin{tabular}{cc}
\hline Japanese Type & Non-Japanese Type \\
\hline Mostly seen in males & Elderly female in Asians and younger in West \\
"Pure" form is predominant & "Mixed" form is predominant \\
Asymptomatic and benign & Complications may occur \\
T-wave negativity is more pronounced & Less pronounced \\
Increased hypertrophy confined to apex & Segmental distribution may occur. Basal septal \\
& hypertrophy producing sub aortic obstruction in \\
& obstruction in 25\%, apical septal hypertrophy with \\
& apical obliteration in $25 \%$ of cases. Occasionally, \\
papillary muscle hypertrophy alone may be seen
\end{tabular}

apical septum and producing a classical "ace of spades sign" in apical four chamber [47] views as shown in Figure 3 and Figure 4. In apical long axis view as shown in Figure 7 and parasternal long axis view as in Figure 8, it is seen as concentric LVH pattern of apex with a spade shaped LV cavity and thus, resulting a heterogeneous appearance in echocardiographic images of various views. Interestingly, spade shaped configuration of LV cavity is visualized in all views in both systolic and diastolic images as assessed by the movement of mitral valve. Kitaoka et al., demonstrated that the wall thickness at the apex was greater in Americans $(23 \pm 4 \mathrm{~mm})$ than in the Japanese patients $(18 \pm 2 \mathrm{~mm})$. Duygu et al. showed that mean maximum apical thickness was $18 \mathrm{~mm}$ in a review of 17 patients with apical HCM. Figure 3 shows a maximum apical thickness $55.3 \mathrm{~mm}$ in apical 4 chamber view of this patient in end-diastolic image. The anterior mitral leaflet is long and elongated and mildly regurgitant as shown in Figure 5 due to trauma as a result of contact with septum as shown in Figures 4 .

Lateral wall thickening was smooth, homogeneous, non-trabeculated in apical HCM and thus differentiated from non-compacted LV (left ventricular) cardiomyopathy and apical HCM may mimic as apical LV thrombus which may be associated with wall motion abnormality. It can also mimic LV EMF (Endomyocardial fibrosis), but EMF is characterized with firm, rolled edges and a rugose surface over the endocardium.

\subsection{Treatment}

Apical HCM is generally associated with good prognosis in both Asian and Caucasian population and a long-term mortality is $0.1 \%$ per year. The approach to management of apical HCM depends on symptoms and risk of sudden cardiac death (SCD). There is lesser incidence of sudden cardiac death in apical variant, compared to patients with normal variant HCM.

In asymptomatic patients, no specific therapy has been outlined, but counseling is certainly recommended for symptomatic monitoring to notice any syncope or presyncopal events on follow up. The medical regimen in symptomatic patients primarily consists of beta-blockers, which have been shown to decrease symptoms as well as 
overall mortality [48].

The major clinical features associated with increased risk of SCD in HCM patients are non-sustained ventricular tachycardia, maximum $L V$ wall thickness of $\geq 3 \mathrm{~cm}$, family history of SCD at younger age, unexplained syncope, abnormal BP response during exercise and increased left atrial diameter $(>36 \mathrm{~mm})$ as a potential SCD risk modifier. Current guidelines do not recommend ICD (implantable cardioverter defibrillator) implantation as a primary prevention for SCD in apical HCM and these clinical features should be used to assess the prognosis on follow up.

In apical HCM complicated with apical aneurysm formation, the size and symptoms of the aneurysm were ameliorated by sub selective coronary angiography and alcohol injection into the small vessels supplying a limited segment of mid-LV obstructive muscle. Others have reported the use of surgical apical myectomy in similar circumstances [49].

An increased apical thickness of $55.3 \mathrm{~mm}$ indicate massive hypertrophy ( $>50 \mathrm{~mm}$ [50]) and LA dilatation $(51.2 \mathrm{~mm})$ predict this patient as a high risk category and so close monitoring is recommended in cardiologic clinic.

\subsection{Screening of Population}

\subsubsection{Transthoracic Echocardiographic Screening}

Echocardiographic screening of population was done in those individuals having ECG changes of LVH (left ventricular hypertrophy). A mixed form of apical HCM (with involvement of IVS) was found in a 65-year-old asymptomatic hypertensive female as shown in Figure 11, Figure 12 and a mid-cavity form of hypertrophic cardiomyopathy as shown in Figures 13 was detected in a 60-year-old aymptomatic normotensive male, having a similar ECG features of LVH in both cases. A mid-cavity type of HCM is also found in a 65-year-old asymptomatic normotensive female with a normal ECG pattern as shown in Figure 14 and Figure 15. Occasionally, papillary muscle hypertrophy alone may be seen as shown in Figure 16. An isolated basal hypertrophy of the interventricular septum in a 61-year-old, hypertensive male with normal ECG is detected by transthoracic echocardiography as shown in Figure 17.

A 60-year-old hypertensive woman having a mid-ventricular obstructive form of HCM with LVH (left ventricular hypertrophy) ECG pattern was observed and the gradient of obstruction may mimic apical dyskinesis with aneurysm as shown in Figures 18-22. The woman developed sudden onset of angina with an elevation in blood pressure up to $160 / 90 \mathrm{mmHg}$ and cardiac enzymes (CK-MB fraction rises to $125 \mathrm{IU} / \mathrm{L}-$ normal $<25$ IU/L). The ECG during the event showed LVH (left ventricular hypertrophy) pattern with VPCs (ventricular premature complexes) as shown in Figure 22 and no evidence of ST-segment elevation and wall motion abnormalities, but with a mild increase in gradient of obstruction in the LV apex as shown in Figure 20 and Figure 21 and it was controlled with antihypertensive medications such as calcium channel blockers and anti-anginal drugs with nitrates. Coronary angiography and selective alcohol injection into the small vessels supplying the mid- segment of left ventricle is preferred in this patient to prevent further episodes. This type of mid-ventricular obstructive 


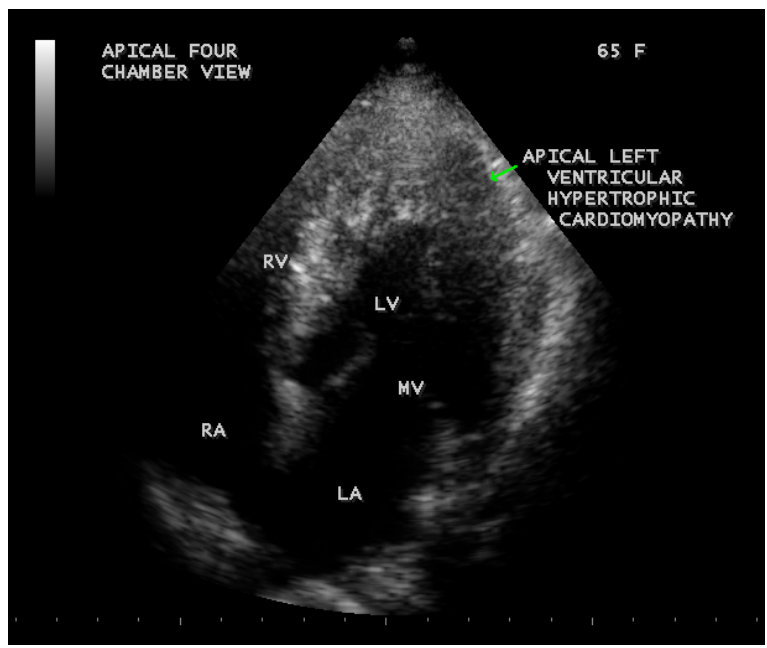

Figure 11. Showing the apical hypertrophic cardiomyopathy in a 65-year-old hypertensive female in apical four chamber view. Arrow mark indicates the lateral wall hypertrophy of LV (left ventricular) apex.

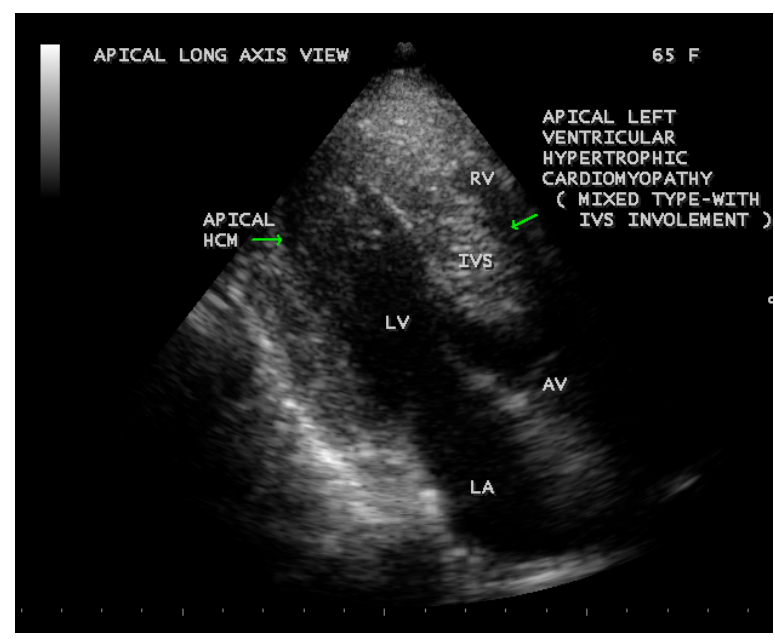

Figure 12. Apical HCM (hypertrophic cardiomyopathy) with involvement of IVS (interventricular septum) ("mixed type")— “Bird's Beak" LV (left ventricular) cavity in Apical long axis view in a 65-year-old hypertensive female. Left arrow indicates lateral wall hypertrophy of apical region and right arrow indicates septal hypertrophy of left ventricle.

form of HCM (hypertrophic cardiomyopathy) is frequently observed in elderly hyperensives with LVH (left ventricular) pattern of ECG changes and more prone to complications such as ischemia and infarction.

\subsubsection{Genetic Screening}

Genetic screening may be done in younger population if there is a family history of sudden death since hypertrophic cardiomyopathy (HCM) is the most common cause of 


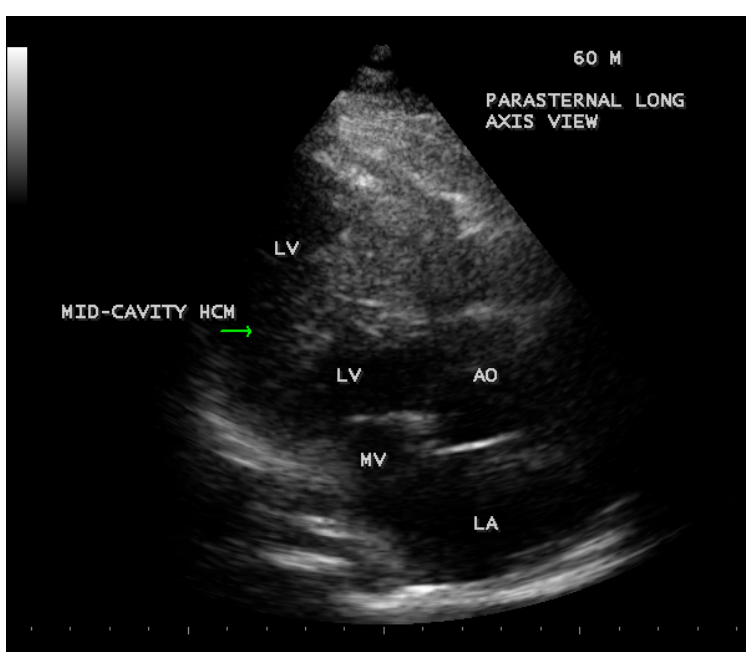

Figure 13. Hypertrophic cardiomyopathy (HCM)"mid-cavity type" in parasternal long axis view in a 60year-old normotensive male. Arrow mark indicates hypertrophy of mid-lateral wall of LV (left ventricle).

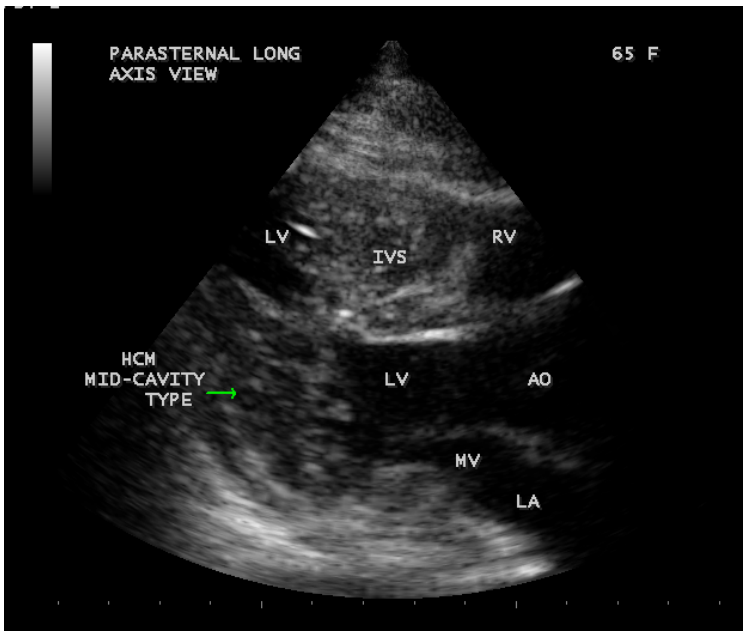

Figure 14. Mid-cavity HCM (hypertrophic cardiomyopathy) in a 65-year-old normotensive, asymptomatic female. Arrow mark indicates hypertrophy of mid-lateral wall of LV.

death in competitive athletes [51]. It is believed that hypertrophy in HCM is a compensatory phenomenon that occurs in response to mutant myosin protein peptide. By inhibiting transcription or translation of mRNA of this mutant allele, it is possible to induce regression of cardiac hypertrophy by abolishing the synthesis of this mutant peptide. The heart is capable to renew the proteins and the myosin, the longest lasting protein has a half-life of 5 days. There is an inherent potential for corrective resynthesis and inhibition of defective gene in adults and hypertrophy may revert it into normal within weeks to months. The ACE (angiotensin-converting enzyme) gene plays a remote role in the development of hypertrophy and ACE inhibitors may be given in those 


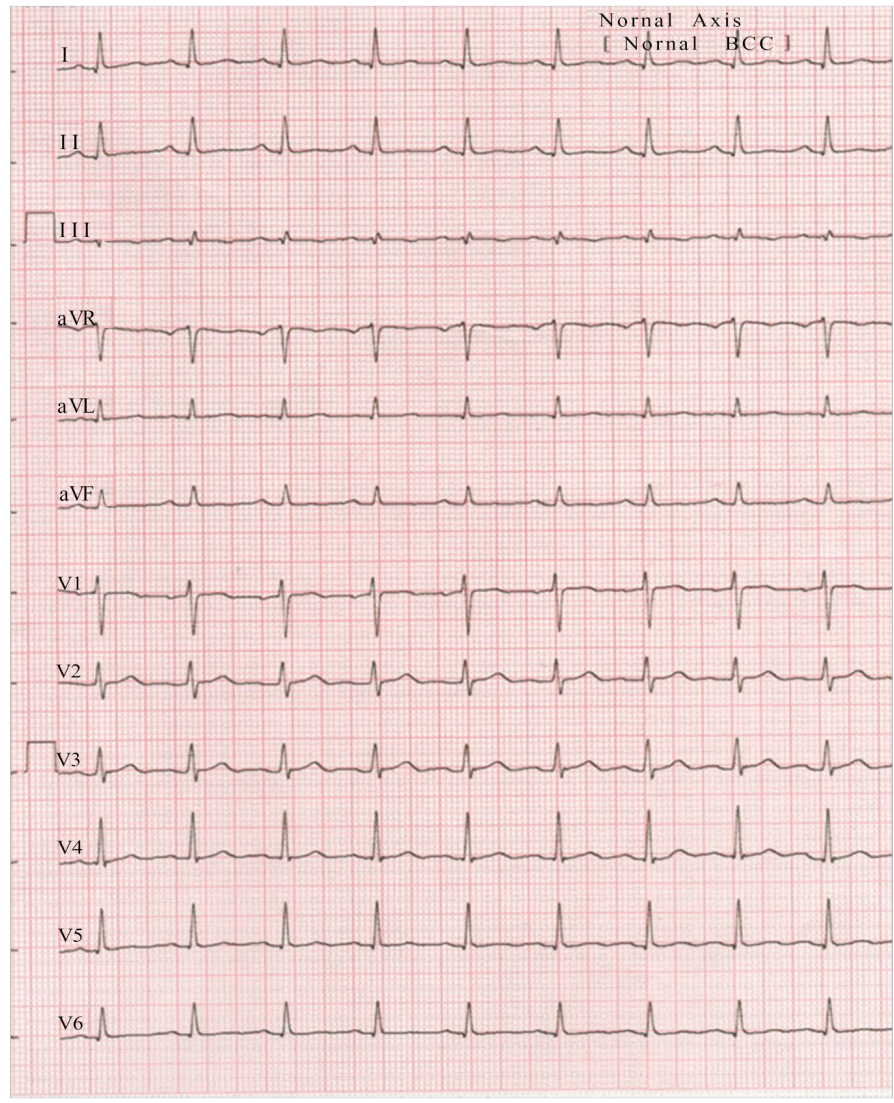

Figure 15. Showing the normal ECG pattern in the 65-year-old asymptomatic normotensive female having the mid-ventricular HCM (hypertrophic cardiomyopathy. $1 \mathrm{mV}=5 \mathrm{~mm}$ standardization).

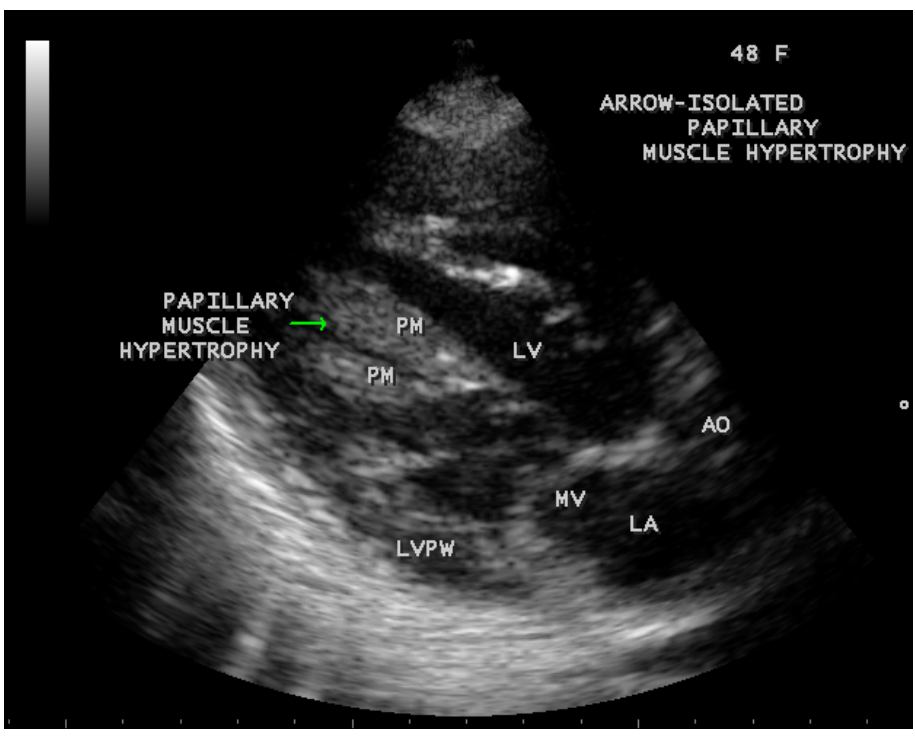

Figure 16. Showing the isolated papillary muscle hypertrophy in the left ventricle (arrow) in a 48-year-old normotensive female in Parasternal long axis view. 


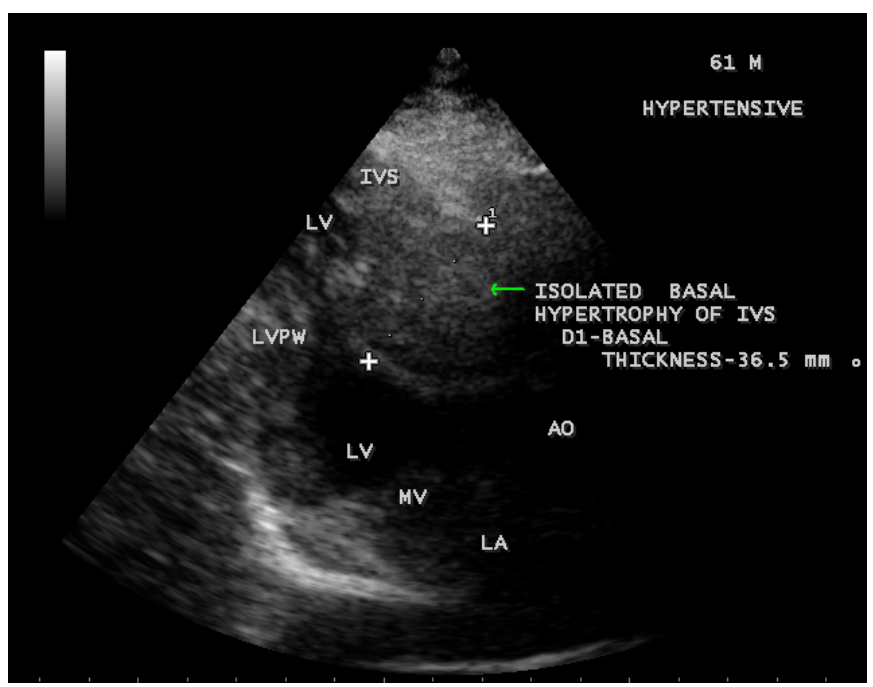

Figure 17. Arrow shows "Isolated basal hypertrophy" of interventricular septum (thickness-36.5 mm) in a 61-year-old hypertensive male in Parasternal long axis view).

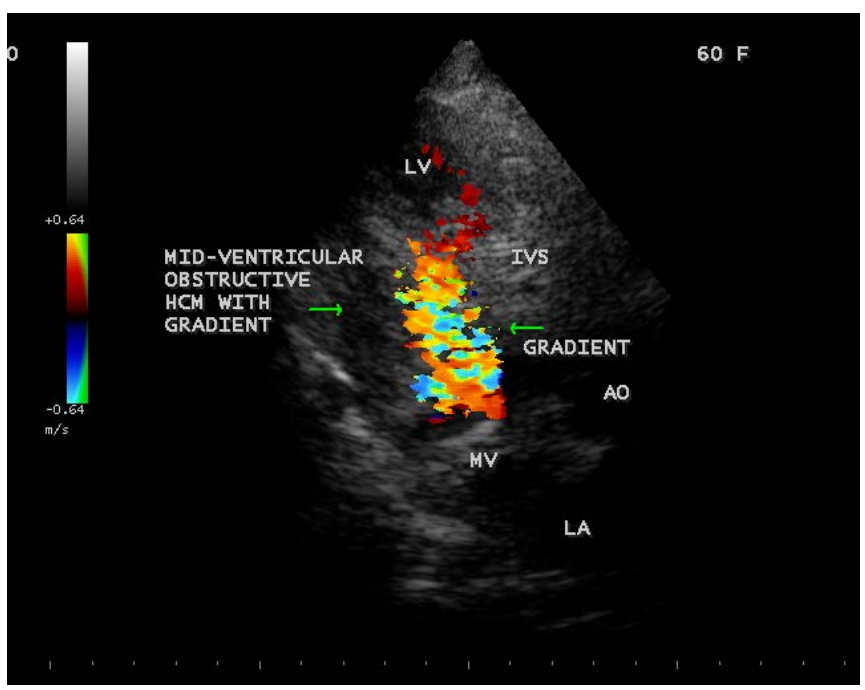

Figure 18. Showing the gradient of obstruction in a 60 -year-old female having mid-ventricular obstructive HCM. Left arrow indicates mid-lateral wall hypertrophy and right arrow indicates the turbulence of flow (gradient) suggesting the obstruction.

individuals without outflow tract obstruction. The exact molecular pathogenesis of HCM is to be determined and so the definite therapy based on gene manipulation remains speculative.

\section{Conclusion}

The initial echocardiographic evaluation was sufficient to diagnose the patients with apical HCM [52]. Typical ECG changes are the signs of left ventricular hypertrophy such as pronounced negative $\mathrm{T}$ waves $(>1 \mathrm{mV})$ in the precordial leads and a positive 


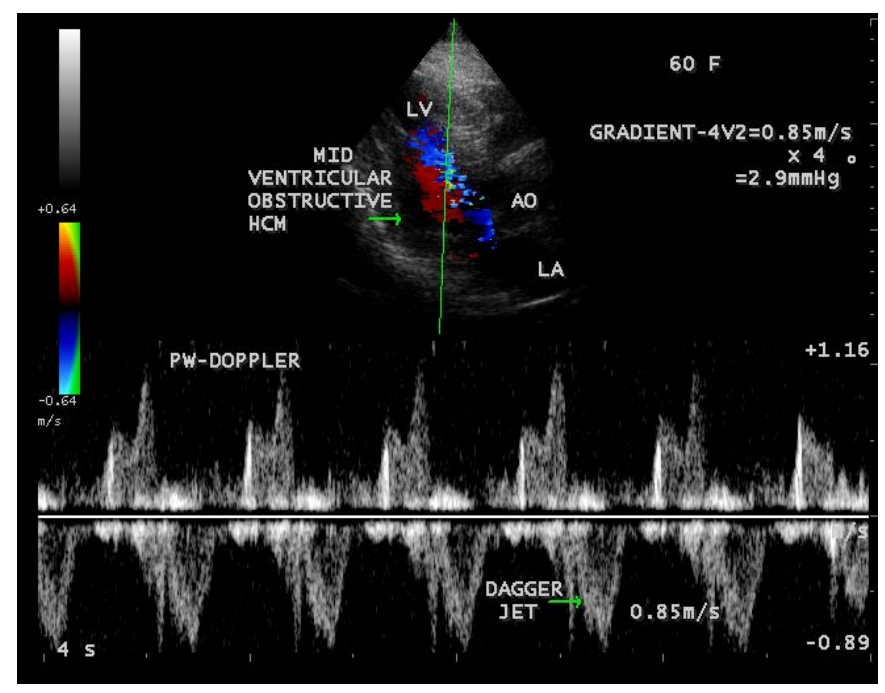

Figure 19. The Pulsed-Doppler imaging. Arrows show the dagger jet with late systolic peak and a minimal gradient of obstruction.

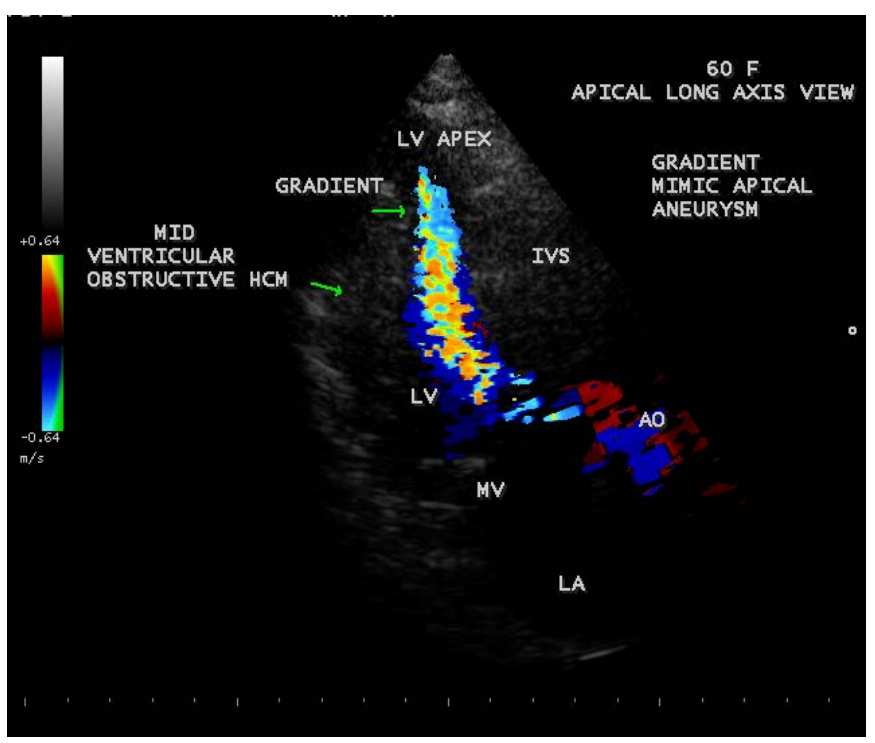

Figure 20. Apical left ventricular long axis view showing the gradient in LV apex mimicking apical aneurysm when the woman developed angina of sudden onset masquerading as "apical ballooning syndrome". Upper arrow indicates the apical gradient and lower lateral arrow indicate mid-lateral wall hypertrophy.

Sokolow-Lyon index. The diagnosis of apical hypertrophic cardiomyopathy was primarily made from ECG changes and specific morphologic criteria as assessed non-invasively by Transthoracic echocardiography. The condition should be considered when encountering a 12-lead ECG showing giant T-wave inversion [53] and it was found that giant inverted T wave was associated with a severe form of apical HCM [54]. The echocardiographic findings may vary with the extension of hypertrophy and in apical HCM; the obliteration of apical cavity by the hypertrophy resulting in a spade-shaped LV (left 


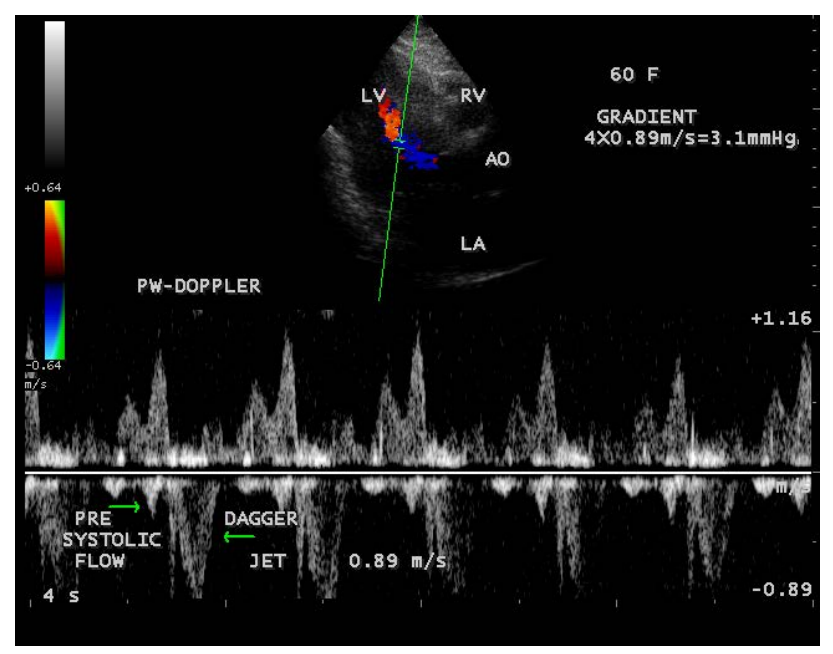

Figure 21. Pulsed-Doppler imaging shows the dagger jet (right arrow) of mild increase in gradient with a presystolic forward flow (left arrow) due to atrial systole during the event of angina.

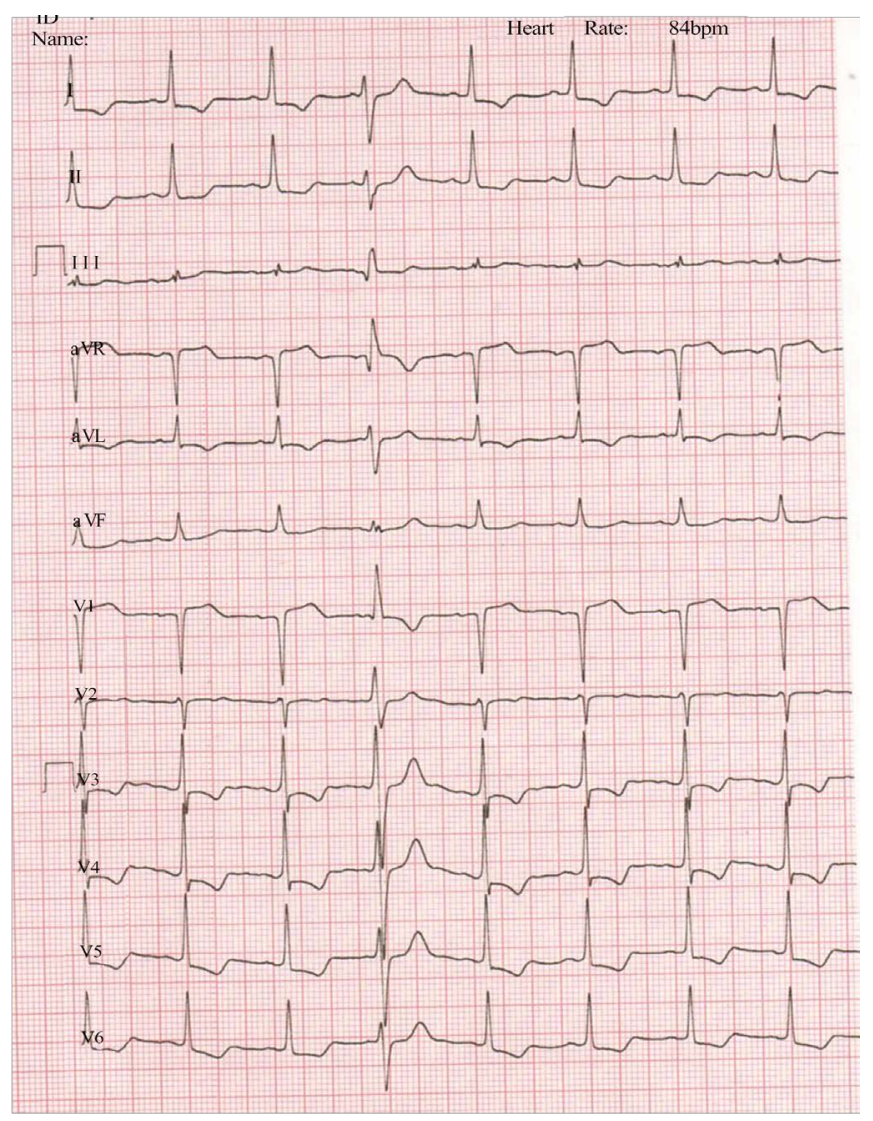

Figure 22. ECG showing LVH (left ventricular hypertrophy pattern-SV $\mathrm{SV}_{1}+\mathrm{RV}_{5}=46 \mathrm{~mm}$, a positive Sokolow-Lyon index and a strain pattern of $2 \mathrm{~mm}$ J point depression with $4 \mathrm{~mm}$ T-wave inversion) and no ST-segment elevation during the angina episode, VPCs (ventricular premature complexes seen during the event $(1 \mathrm{mV}=5$ $\mathrm{mm}$ standardization). 
ventricular) cavity in all views of echocardiographic imaging was recognized and it remained aymptomatic in this 54-year-old male at this belt of Thoothu- kudi in India. The mixed and mid-cavity forms were detected in this region with a relatively benign and late onset disease in adult life. Mid-ventricular obstructive form with an anginal episode was also reported in an elderly hypertensive female at the age of 60 years old.

\section{References}

[1] Kitaoka, H., Doi, Y., Casey, S.A., Hitomi, N., Furuno, T. and Maron, B.J. (2003) Comparison of Prevalence of Apical Hypertrophic Cardiomyopathy in Japan and the United States. American Journal of Cardiology, 92, 1183-1186. http://dx.doi.org/10.1016/j.amjcard.2003.07.027

[2] Sakamoto, T., Tei, C., Murayama, M., et al. (1976) Giant T Wave Inversion as a Manifestation of Asymmetrical Apical Hypertrophy of the Left Ventricle: Echocardiographic and Ultrasono-Cardiotomographic Study. Japanese Heart Journal, 17, 611-629. http://dx.doi.org/10.1536/ihj.17.611

[3] Yamaguchi, H., Ishimura, T., Nishiyama, S., et al. (1979) Hypertrophic Cardiomyopathy with Giant Negative T Waves (Apical Hypertrophy): Ventriculographic and Echocardiographic Features in 30 Patients. American Journal of Cardiology, 44, 401-412. http://dx.doi.org/10.1016/0002-9149(79)90388-6

[4] Kubo, T., Kitaoka, H., Okawa, M., et al. (2009) Clinical Profiles of Hypertrophic Cardiomyopathy with Apical Phenotype-Comparision of Pure-Apical Form and Distal-Dominant Form. Circulation Journal, 73, 2330-2336. http://dx.doi.org/10.1253/circj.CJ-09-0438

[5] Chen, C.C., Lei, M.H., Hsu, Y.C., Chung, S.L. and Sung, Y.J. (2011) Apical Hypertrophic Cardiomyopathy Correlations Between Echocardiographic Parameters, Angiographic Left Ventricular Morphology, and Clinical Outcomes. Clinical Cardiology, 34, 233-238. http://dx.doi.org/10.1002/clc.20874

[6] Hada, Y., Sakamoto, T., Amano, K., Yamaguchi, T., Takenaka, K., Takahoshi, H., et al. (1987) Prevalence of Hypertrophic Cardiomyopathy in a Population of Adult Japanese Workers as Detected by Echocardiographic Screening. American Journal of Cardiology, 59, 183-184. http://dx.doi.org/10.1016/S0002-9149(87)80107-8

[7] Reddy, V., Korcarz, C., Weinert, L., et al. (1998) Apical Hypertrophic Cardiomyopathy. Circulation, 98, 2354. http://dx.doi.org/10.1161/01.CIR.98.21.2354

[8] Maron, B.J. (2002) Hypertrophic Cardiomyopathy: A Systematic Review. JAMA, 287, 13081320. http://dx.doi.org/10.1001/jama.287.10.1308

[9] Chikamori, T., Doi, Y.L., Akizawa, M., Yonezawa, Y., Ozawa, T. and Mckenna, W.J. (1992) Comparison of Clinical, Morphological, and Prognostic Features in Hypertrophic Cardiomyopathy between Japanese and Western Patients. Clinical Cardiology, 15, 833-837. http://dx.doi.org/10.1002/clc.4960151108

[10] Yan, L., Wang, Z., Xu, Z., Li, Y., Tao, Y. and Fan, C. (2012) Two Hundred Eight Patients with Apical Hypertrophic Cardiomyopathy in China: Clinical Feature, Prognosis, and Comparison of Pure and Mixed Forms. Clinical Cardiology, 35, 101-106. http://dx.doi.org/10.1002/clc.20995

[11] Lee, C.H., Liu, P.Y., Lin, L.J., et al. (2006) Clinical Features and Outcome of Patients with Apical Hypertrophic Cardiomyopathy in Taiwan. Cardiology, 106, 29-35. http://dx.doi.org/10.1159/000092590

[12] Sakamoto, T. (2001) Apical Hypertrophic Cardiomyopathy (Apical Hypertrophy): An 
Overview. Journal of Cardiology, 37, 161-178.

[13] Marian, A.J. and Roberts, R. (1995) Recent Advances in the Molecular Genetics of Hypertrophic Cardiomyopathy. Circulation, 92, 1336-1347. http://dx.doi.org/10.1161/01.CIR.92.5.1336

[14] Arad, M., Penas-Lado, M., Monserrat, L., Maron, B.J., Sherrid, M., Ho, C.Y., Barr, S., et al. (2005) Gene Mutations in Apical Hypertrophic Cardiomyopathy. Circulation, 112, 2805 2811. http://dx.doi.org/10.1161/CIRCULATIONAHA.105.547448

[15] Kishimoto, C., Takada, H., Hiraoka, Y., et al. (1996) HLA-DR 2 Antigen Linkage in Patient with Apical Hypertrophic Cardiomyopathy in Japan. Cardiology, 87, 488-491. http://dx.doi.org/10.1159/000177143

[16] Webb, J.G., Sasson, Z., Rakowski, H., et al. (1990) Apical Hypertrophic Cardiomyopathy, Clinical Follow up and Diagnostic Correlates. Journal of American College of Cardiology, 15, 83-90. http://dx.doi.org/10.1016/0735-1097(90)90180-W

[17] Maron, B.J., Gross, B.W. and Stark, S.I. (1995) Extreme Left Ventricular Hypertrophy. Circulation, 92, 2748. http://dx.doi.org/10.1161/01.CIR.92.9.2748

[18] Alfonso, F., Nihoyannopoulos, P., Stewart, J., et al. (1990) Clinical Significance of Giant Negative T Waves in Hypertrophic Cardiomyopathy. Journal of American College of Cardiology, 15, 965-971. http://dx.doi.org/10.1016/0735-1097(90)90225-E

[19] Maron, B.J. (1993) Hypertrophic Cardiomyopathy. Current Problems in Cardiology, 18, 639-704. http://dx.doi.org/10.1016/0146-2806(93)90025-W

[20] Skinner, J.R., Manzoor, A., Heyes, A.M., et al. (1997) A Regional Study of Presentation and Outcome of Hypertrophic Cardiomyopathy in Infants. Heart, 77, 229-233. http://dx.doi.org/10.1136/hrt.77.3.229

[21] Maron, B.J., Verter, J. and Kapur, S. (1978) Disproportionate Ventricular Septal Thickening in the Developing Normal Human Heart. Circulation, 57, 520-526. http://dx.doi.org/10.1161/01.CIR.57.3.520

[22] Maron, B.J. (1997) Hypertrophic Cardiomyopathy. Lancet, 350, 127-133. http://dx.doi.org/10.1016/S0140-6736(97)01282-8

[23] Nimura, H., Bachinski, L.L., Sangwatanaroj, S., et al. (1998). Mutations in the Gene for Cardiac Myosin-Binding Protein C and Late-Onset Familial Hypertrophic Cardiomyopathy. New England Journal of Medicine, 338, 1248-1257. http://dx.doi.org/10.1056/NEJM199804303381802

[24] Gruner, C., Care, M., Siminovitch, K., Moravsky, G., Wigle, E.D., Woo, A. and Rakowski, H. (2011) Sarcomere Protein Gene Mutations in Patients with Apical Hypertrophic Cardiomyopathy. Circulation Cardiovascular Genetics Journal, 4, 288-295. http://dx.doi.org/10.1161/CIRCGENETICS.110.958835

[25] Choi, E.Y., Rim, S.J., Ha, J.W., Kim, Y.J., Lee, S.C., Kang, D.H., et al. (2008) Phenotypic Spectrum and Clinical Characteristics of Apical Hypertrophic Cardiomyopathy: Multicenter Echo-Doppler Study. Cardiology, 110, 53-61. http://dx.doi.org/10.1159/000109407

[26] Abinader, E.G., Rauchfleisch, S. and Naschitz, J. (1982) Hypertrophic Apical Cardiomyopathy A Subtype of Hypertrophic Cardiomyopathy. Israel Journal of Medical Sciences, 18, 1005-1009.

[27] Matsumori, A., Ohashi, N. and Sasayama, S. (1998) Hepatitis C Virus Infection and Hypertrophic Cardiomyopathy. Annals of Internal Medicine, 129, 749-750. http://dx.doi.org/10.7326/0003-4819-129-9-199811010-00025

[28] Louie, E.K. and Maron, B.J. (1987) Apical Hypertrophic Cardiomyopathy: Clinical and 
Two-Dimensional Echocardiographic Assessment. Annals of Internal Medicine, 106, 663670. http://dx.doi.org/10.7326/0003-4819-106-5-663

[29] Maron, B.J., Spirito, P., Wesley, Y. and Arce, J. (1986) Development and Progression of Left Ventricular Hypertrophy in Children with Hypertrophic Cardiomyopathy. New England Journal of Medicine, 315, 610-614. http://dx.doi.org/10.1056/NEJM198609043151003

[30] Klarich, K.W., Attenhofer Jost, C.H., Binder, J., Connolly, H.M., Scott, C.G., Freeman, W.K., Ackerman, M.J., et al. (2013) Risk of Death in Long-Term Follow-Up of Patients with Apical Hypertrophic Cardiomyopathy. American Journal of Cardiology, 111, 1784-1791. http://dx.doi.org/10.1016/j.amjcard.2013.02.040

[31] Eriksson, M.J., Sonnenberg, B., Woo, A., Rakowski, P., Parker, T.G., Wigle, E.D., et al. (2002) Long-Term Outcome in Patients with Apical Hypertrophic Cardiomyopathy. Journal of American College of Cardiology, 39, 638-645. http://dx.doi.org/10.1016/S0735-1097(01)01778-8

[32] Prsad, K., Atherton, J., Smith, G.C., Mckenna, W.J., Frenneaux, M.P. and Nihoyannopoulos, P. (1999) Echocardiographic Pitfalls in the Diagnosis of Hypertrophic Cardiomyopathy. Heart, 82, 1108-1115. http://dx.doi.org/10.1136/hrt.82.2008.iii8

[33] Duygu, H., Zoghi, M., Nalbantgil, S., Ozerkan, F., Akilli, A., Akin, M., et al. (2008) Apical Hypertrophic Cardiomyopathy Might Lead to Misdiagnosis of Ischemic Heart Disease. International Journal of Cardiovascular Imaging, 24, 675-681. http://dx.doi.org/10.1007/s10554-008-9311-7

[34] Kulkreti, B.B., Ramakrishnan, S., Gulati, G.S., Bhargava, B. and Seth, S. (2012) Calcified Aneurysm of Left Ventricular Apex in Apical Cardiomyopathy. Texas Heart Institute Journal, 39, 758-760.

[35] Wigle, E.D., Rakowski, H., Kimball, B.P., et al. (1995) Hypertrophic Cardiomyopathy, Clinical Spectrum and Treatment. Circulation, 92, 1680-1692. http://dx.doi.org/10.1161/01.CIR.92.7.1680

[36] Usui, M., Inoue Suzuki, J., et al. (1993) Relationship between Distribution of Hypertrophy and Electrocardiographic Changes in Hypertrophic Cardiomyopathy. American Heart Journal, 126, 177-183. http://dx.doi.org/10.1016/S0002-8703(07)80026-3

[37] Hayden, G.E., Brady, W.J., Perron, A.D., Somers, M.P. and Mattu, A. (2002) Electrocardiographic T-Wave Inversions: Differential Diagnosis in the Chest Pain Patient. American Journal of Emergency Medicine, 20, 252-262. http://dx.doi.org/10.1053/ajem.2002.32629

[38] Nishiyama, S., Shiratori, K., Nishimura, S., Araki, R., Takeda, K., et al. (1984) Correlation Between Left Ventricular Wall Thickness and the Depth of Negative T Wave in Apical Hypertrophic Cardiomyopathy. Journal of Cardiography, 14, 281-288.

[39] Ciro, E., Nichols, P.F. and Maron, B.J. (1983) Heterogeneous Morphologic Expression of Genetically Transmitted Hypertrophic Cardiomyopathy, Two-Dimensional Echocardiography. Circulation, 67, 1227-1233. http://dx.doi.org/10.1161/01.CIR.67.6.1227

[40] Maron, B.J., Bonow, R.O., Seshagiri, T.N., et al. (1982) Hypertrophic Cardiomyopathy with Ventricular Septal Hypertrophy Localized to the Apical Region of the Left Ventricle (Apical Hypertrophic Cardiomyopathy). American Journal of Cardiology, 49, 1838-1848. http://dx.doi.org/10.1016/0002-9149(82)90200-4

[41] Stainback, R.F. (2012) Apical Hypertrophic Cardiomyopathy. Texas Heart Institute Journal, 39, 747-749.

[42] Diaconu, C.C., Dumitru, N., Fruntelata, A.G., Lacau, S. and Bartos, D. (2015) Apical Hypertrophic Cardiomyopathy: The Ace-of-Spades as the Disease Card. Acta Cardiologica Sinica, 31, 83-86. 
[43] Chun, E.J., et al. (2010) Hypertrophic Cardiomyopathy. Assessment with MR imaging and Multi-Detector CT. Radiographics, 30, 1309-1328. http://dx.doi.org/10.1148/rg.305095074

[44] Suzuki, J., Watanabe, F., Takenaka, K., et al. (1993) New Subtype of Apical Hypertrophic Cardiomyopathy Identified with Nuclear Magnetic Resonance Imaging as an Underlyiong Cause of Markedly Inverted T Waves. Journal of American College of Cardiology, 22, 11751181. http://dx.doi.org/10.1016/0735-1097(93)90434-3

[45] Suzuki, J., Shimamoto, R., Nishikawa, J., et al. (1999) Morphological Onset and Early Diagnosis in Apical Hypertrophic Cardiomyopathy. A Long-Term Analysis with Nuclear Magnetic Resonance Imaging. Journal of American College of Cardiology, 33, 146-151. http://dx.doi.org/10.1016/S0735-1097(98)00527-0

[46] Flett, A.S., Maestrini, V., Milliken, D., Fontana, M., Treibel, T.A., Harb, R., Sado, D.M., Quarta, G., Herrey, A., Sneddon, J., Elliott, P., McKenna, W. and Moon, J.C. (2015) Diagnosis of Apical Hypertrophic Cardiomyopathy: T-Wave Inversion and Relative but Not Absolute Apical Left Ventricular Hypertrophy. International Journal of Cardiology, 183, 143-148. http://dx.doi.org/10.1016/j.ijcard.2015.01.054

[47] Chaturvedi, H. (2015) Apical Hypertrophic Cardiomyopathy with Hemodynamically Unstable Ventricular Arrhythmia: Atypical Presentation. EC (E-CRONICON) Cardiology, 2, 106-110.

[48] Kim, S.H., Kim, S.O., Han, S., Hwang, K.W., Lee, C.W., Nam, G.B., et al. (2013) Long-Term Comparison of Apical versus Asymmetric Hypertrophic Cardiomyopathy. International Heart Journal, 54, 207-211. http://dx.doi.org/10.1536/ihj.54.207

[49] Schaff, H.V., Brown, M.L., Dearani, J.A., Abel, M.D., Ommen, S.R., Sorajja, P., et al. (2010) Apical Myectomy: A New Surgical Technique for Management of Severely Symptomatic Patients with Apical Hypertrophic Cardiomyopathy. Journal of Thoracic and Cardiovascular Surgery, 139, 634-640. http://dx.doi.org/10.1016/j.jtcvs.2009.07.079

[50] Maron, B.J., Pelliccia, A. and Spirito, P. (1995) Cardiac Disease in Young Trained Athletes. Insights into Methods for Distinguishing Athlete's Heart from Structural Heart, with Particular Emphasis on Hypertrophic Cardiomyopathy. Circulation, 91, 1596-1601. http://dx.doi.org/10.1161/01.CIR.91.5.1596

[51] Maron, B.J., Epstein, S.E. and Roberts, W.C. (1986) Causes of Sudden Death in Competitive Athletes. Journal of American College of Cardiology, 7, 204-214. http://dx.doi.org/10.1016/S0735-1097(86)80283-2

[52] Rodgers-Fischl, P., Kolodziej, A.R., Sorrell, V.L. and Rugg, S.S. (2016) Apical Hypertrophic Cardiomyopathy in an African American. A Case Presentation and Literature Review. Journal of Cardiology \& Clinical Research, 4, 1056.

[53] Courtney, R., Usry, D.O., Sean, P. and Javaheri, D.O. (2015) Apical Hypertrophic Cardiomyopathy. Consultant, 55, 1022-1027.

[54] Park, S.Y., Park, T.H., Kim, J.H., Baek, H.K., Seo, J.M., Kim, W.J., et al. (2010) Relationship between Giant Negative T-Wave and Severity of Apical Hypertrophy in Patients with Apical Hypertrophic Cardiomyopathy. Echocardiography, 27, 770-776. http://dx.doi.org/10.1111/j.1540-8175.2010.01152.x 
Submit or recommend next manuscript to SCIRP and we will provide best service for you:

Accepting pre-submission inquiries through Email, Facebook, LinkedIn, Twitter, etc. A wide selection of journals (inclusive of 9 subjects, more than 200 journals)

Providing 24-hour high-quality service

User-friendly online submission system

Fair and swift peer-review system

Efficient typesetting and proofreading procedure

Display of the result of downloads and visits, as well as the number of cited articles

Maximum dissemination of your research work

Submit your manuscript at: http://papersubmission.scirp.org/

Or contact crcm@scirp.org 